\title{
Delirium in critically ill patients: risk factors modifiable by nurses
}

\author{
Delírium no doente crítico: fatores de risco modificáveis pelos enfermeiros \\ El delirio en pacientes críticos: factores de riesgo modificables por los enfermeros
}

Jorge Miguel Pereira*; Francisco José Dos Reis Barradas**; Rodrigo Miguel Caetano Sequeira***; Maria do Céu Mendes Pinto Marques***; Marco Job Batista*****; Manuel Galhardas ${ }^{* * * * * *}$; Marco Santinho Santos ${ }^{* * * * * * *}$

\begin{abstract}
Background: Delirium is one the most prevalent mental disorders in patients hospitalized due to acute conditions and is an important independent predictor of poor outcomes.

Objectives: This study aimed to identify the risk factors modifiable by nurses, which are associated with the development of delirium in patients hospitalized in a level 2 intensive care unit of a central hospital.

Methodology: We conducted an exploratory-descriptive study, with an intentional sample of 57 inpatients. The Confusion Assessment Method for the Intensive Care Unit scale (CAM-ICU) was applied and clinical and other data were collected.

Results: We identified several variables as risk factors potentially modifiable by nurses, including promotion of nutrition and hydration, management of medical devices, promotion of family visits, promotion of the use of prostheses, proper management of prescribed medication; promotion of proper positioning and oxygen therapy.

Conclusion: The presence of delirium is still undervalued by nurses. However, they can call attention to the implementation of measures aimed to reduce delirium. To this end, the assessment of delirium in intensive care patients should be systemized.
\end{abstract}

Keywords: delirium; risk factors; nurse; critical care

\section{Resumo}

Enquadramento: O delírium está entre as doenças mentais mais prevalentes nos doentes hospitalizados por patologia aguda, e é um importante preditor independente de prognóstico negativo. Objetivos: Identificar os fatores de risco modificáveis pelos enfermeiros, associados ao desenvolvimento de delírium nos doentes internados numa unidade de cuidados intensivos nível II de um hospital central. Metodologia: Realizou-se um estudo exploratório-descritivos, onde foi aplicada a escala Confusion Assessment Method for the Intensive Care Unit (CAM-ICU) e recolhidos dados de cariz clínico e outros complementares de 57 doentes internados, selecionados de forma intencional.

Resultados: Identificaram-se variáveis como fatores de risco potencialmente modificáveis pelos enfermeiros, nomeadamente promoção da nutrição e hidratação, gestão de dispositivos clínicos, promoção da visita de familiares, favorecimento da utilização de próteses, gestão adequada da medicação prescrita; favorecimento de posicionamentos e oxigenoterapia adequados. Conclusão: A presença de delírium ainda é subvalorizada pelos enfermeiros. No entanto, estes podem advertir para a implementação de medidas que diminuam o delírium. Posto isto, deve-se sistematizar a avaliação do delírium nos doentes internados em unidades de cuidados intensivos.

Palavras-chave: delirium; fatores de risco; enfermeiro; cuidados intensivos

"RN., Nurse Specialist in Medical-Surgical Nursing, Postgraduate Degree in Emergency and Trauma, Emergency Department of the Hospital José Joaquim Fernandes, 7801-849, Beja, Portugal [jorgepere15@gmail.com]. Contributio the article: Iiterature search, data collection and analysis, statistical treatment, discussion and article writing. Addre.s for correspondence. Rua D. Antonio Fennando Covas Lama, 7801-849, Beja, Portuga "RN., Nurse Specialist in Medical-Surgical Nursing, Emergency Department of the Hospital José Joaquim Fernandes 7801-849, Beja, Portugal [xkobradas@gmail.com]. Contril *** RN., Nurse Specialist in Medical-Surgical Nursing, Emergency Department of the Hospital José Joaquim Fernande 7801-849, Beja, Portugal [rmcaetanoster@gmail.com]. Contribution to the article: literature search, data collection and

analysis, statistical treatment, discussion and article writing.
${ }_{* * * * *}$ Ph.D., Coordinating Professor, S. Joäo de Deus School of Nursing, 7000-811, Evora, Portugal [mcmarques@ @uevora

pt]. Contribution to the article: review, analysis, discussion and article writing. 2805-267, Almada, Portugal [marco.batista@hgo.min-saude.pt]. Contribution to the article: review, analysis, discussion and article writing.

****** MSc., Nurse Specialist in Medical-Surgical Nursing, Hospital Garcia de Orta, 2805-267, Almada, Portugal [kikogathardas@gmail.com]. Contribution to the article: review, analysis, discussion and article writing 1905. Mrc, Nurse Specialist in Medical-surgical Nursing, Immediate Difierentiated Care Unit, Hospital Garcia de Orta article writing.

\section{Resumen}

Marco contextual: El delirio es uno de los trastornos mentales con más prevalencia en los pacientes hospitalizados por patología aguda y es un predictor independiente importante de mal pronóstico.

Objetivos: Identificar los factores de riesgo modificables por los enfermeros, asociados con el desarrollo del delirio en pacientes hospitalizados en una unidad de cuidados intensivos nivel II de un hospital central.

Metodología: Se llevó a cabo un estudio exploratorio-descriptivo, en el cual se aplicó la escala Confusion Assessment Method for the Intensive Care Unit (UCI-CAM) y se recogieron datos de naturaleza clínica y otros datos complementarios de 57 pacientes hospitalizados y seleccionados de forma intencional.

Resultados: Se identificaron las variables como factores de riesgo potencialmente modificables por los enfermeros, principalmente promover la nutrición y la hidratación, gestionar los dispositivos médicos, promover las visitas familiares, favorecer el uso de prótesis, gestionar adecuadamente la medicación prescrita, favorecer el posicionamiento y la oxigenoterapia adecuados. Conclusión: La presencia de delirio todavía está infravalorada por los enfermeros. Sin embargo, estos pueden advertir que se pongan en práctica medidas que reduzcan el delirio. Dicho esto, se debe sistematizar la evaluación del delirio en pacientes hospitalizados en unidades de cuidados intensivos.

Palabras clave: delirio: factores de riesgo; enfermero; cuidados críticos

Received for publication: 25.01 .16

Accepted for publication: 09.05 .16 


\section{Introduction}

Delirium, commonly known as acute confusional state, is one of the most prevalent mental disorders in patients hospitalized for acute disease. According to the National Institute for Health and Care Excellence (NICE, 2014), its prevalence is 30\% in medical wards and $50 \%$ in surgical wards. According to Barr et al. (2013), and Faria and Moreno (2013), the prevalence and incidence of delirium is higher in the intensive care units (ICUs). These authors reported a rate of $60 \%$ in spontaneously breathing patients and of $80 \%$ in patients under mechanical ventilation.

Faria and Moreno (2013) added that, as in other clinical conditions, prevention is better than treatment, since an early intervention allows reducing not only the incidence of delirium, but also its severity and symptom duration. According to the American Association of Critical-Care Nurses (AACCN, 2011), Barr et al. (2013) and NICE (2014), ICUs should have specific policies to assess, prevent and treat delirium, which start by identifying the most vulnerable patients, and the risk factors associated with the development of delirium. It is estimated that a patient hospitalized in an ICU has an average of 10 risk factors for the development of delirium. Some of these factors are considered as non-modifiable factors, i.e. they pre-exist at the time of admission, whereas others are considered as modifiable factors, since they result from acute conditions and/or from iatrogenic/ environmental causes (Faria \& Moreno, 2013). According to NICE (2014), the early intervention in modifiable risk factors is essential in order to decrease the patients' susceptibility to develop delirium.

For the reasons given in their study, Faria and Moreno (2013) emphasized that delirium is an important issue for the safety of patients hospitalized in ICUs. Acknowledging that nurses, namely specialist nurses, have increased responsibilities in this area for possessing specific skills to design and maintain safe therapeutic environments (Regulamento $\mathrm{n}^{\circ}$ 124/2011) and for integrating the Hospital Risk Management Committee, with a view to reducing the "risk of unnecessary healthcare-related harm to acceptable minimum levels", we considered it appropriate to explore this issue (Organização Mundial de Saúde [OMS], 2011, p. 14). Therefore, we set out the objective for our research: To identify risk factors modifiable by nurses associated with the development of delirium in patients hospitalized in the Immediate Differentiated Care Unit of the Hospital Garcia of Orta (IDCU - HGO).

\section{Background}

The European Delirium Association analyzes delirium based on the criteria of the Diagnostic and Statistical Manual of Mental Disorders of the American Psychiatric Association (2014). According to this manual, delirium is a disturbance of consciousness with reduced ability to focus, sustain or shift attention. It implies a change in cognition or the development of a perceptual disturbance that is not better accounted for by a preexisting established or evolving dementia. The disturbance develops over a short period of time (hours to days) and tends to fluctuate during the course of the day. There is evidence that the disturbance is directly caused by a medical condition. With regard to its consequences, the AACCN (2011) and Barr et al. (2013) emphasized that delirium is an important independent predictor of poor outcomes correlated with increased in-hospital mortality at 6 months, increased length of stay in the ICU and in the hospital, prolonged mechanical ventilation dependence, and greater need for endotracheal reintubation. Alongside the abovementioned authors, Faria and Moreno (2013) add that, even after discharge, the long-term cognitive, emotional and functional changes continue over time, with serious consequences for the quality of life of patients and their families. Therefore, other studies have been developed that involve different areas related to this phenomenon, and leading to the implementation of better hospital and community interventions with a view to improving the quality of life of these patients in their return home (Neves, Silva, \& Marques, 2011). From an economic perspective, delirium is estimated to contribute to up 39\% of the ICU costs, with annual costs of around 4 to 16 billion dollars only in the United States of America (AACCN, 2011; Barr et al., 2013). Despite the reported high rates, Faria and Moreno (2013) argue that delirium underdiagnosis is still a reality, particularly in ICUs. According to the these authors, health professionals do not consider this clinical condition in the same way as other organ dysfunctions and about $66 \%$ of the cases can even never be diagnosed, a percentage which amounts to $75 \%$ in 
patients with hypoactive delirium. Underdiagnosis is a problem in the extent that patients with delirium who are not early identified eventually do not receive an appropriate treatment, leading to complications.

In 1990, in order to facilitate the assessment of delirium by other professionals other than psychiatrists, Dr. Sharon Inouve created the Confusion Assessment Method (CAM), which, years later, was adapted to intensive care (CAM-ICU). This simple tool can be applied to patients who are unable to verbalize, because it is based on the observation of behaviors and non-verbal answers to simple questions. According to Barr et al. (2013), in line with the Society of Critical Care Medicine (SCCM), this method is a level A evidence, with a sensitivity of 94\% to 100\% and a specificity of $90 \%$ to $95 \%$, making it one of the quality criteria listed in the NICE guidelines for the diagnosis, prevention and management of delirium (2014).

The application of the CAM-ICU requires the assessment of the patient's level of consciousness through the Richmond Agitation-Sedation Scale (RASS) so as to verify if the patient's confusional state had an acute onset or if there was any fluctuation in the past 24 hours. It also requires the assessment of conscience, namely the presence of inattention and disorganized thinking. According to the Vanderbilt University Medical Center (VUMC, 2011), this method allows assessing delirium in less than 1 minute in 90\% of cases, which facilitates its application in every shift since delirium is characterized as a fluctuating disorder.

Since 2002, the World Health Organization has been urging Member-States to produce scientific evidence that contribute to improving patient safety. Impelled by this need, hospitals have been creating their own risk management committees, in which nurses play an active role, that aim to reduce the risk of "harm resulting from or associated with plans or actions taken during health care provision. .." (OMS, 2011, p. 15).

Given that the quality standards of specialized nursing care to the critically ill patient advocate that "In the constant search for excellence in professional practice, the specialist nurse prevents health complications of the person experiencing complex processes of critical illness and/or organ failure", the research on the factors modifiable by nurses to prevent delirium has not only a legal basis, but also a sense of usefulness and relevance of its functional contents (Regulamento $n^{0} 361 / 2015$, p. 17242).

\section{Research question}

What are the main risk factors modifiable by nurses with an influence on the development of delirium in patients hospitalized in the IDCU-HGO?

\section{Methodology}

This exploratory-descriptive study was developed in the IDCU (level 2 intensive care units) after approval from the Ethics Committee (file no. 287) and authorization from the Board of Directors of the HGO. All ethical and legal procedures were followed in accordance with the Helsinki Declaration. Data were collected through a questionnaire divided into four parts: patient characterization, consciousness level assessed through the RASS, CAM-ICU scale, and other relevant clinical data. Data collection lasted 5 weeks between December 2015 and January 2016.

The sample was intentionally selected by the researchers, taking into account the participants' availability for data collection. The key pre-requisite for including patients in this study was a level of consciousness characterized by a RASS $\geq-3$, condition which allows for the proper application of the CAM-ICU scale (VUMC, 2011). The sample was composed of 57 patients. Some of them were assessed more than once during the course of hospitalization (on different days and times), since delirium is characterized for being a fluctuating condition.

Clinical data were also collected, as well as other complementary data suggested by the literature review and grouped as probable modifiable risk factors for the development of delirium: type of feeding (zero, oral, enteral), family visits during hospitalization, presence of invasive clinical devices, type of medication prescribed for the central nervous system, and uncompensated sensory loss due to the lack of prostheses.

The data were entered and processed using the software Statistical Package for the Social Sciences SPSS, version 22.0. Data were statistically and descriptively analyzed, and the variables were compared so as find associations between them. 


\section{Results}

The sample was composed of 57 patients. Some of the patients were assessed more than once during their hospitalization in the IDCU, in a total of 96 observations.
The mean age of the sample was 67.9 years, with a standard deviation of 13.4. With regard to gender, $67 \%$ were male patients. We found the presence of delirium in 20 (35\%) of the 57 patients assessed. Table 1 assembles the data that characterize the study sample.

Table 1

Sample characterization, $n=57$

\begin{tabular}{lc}
\hline & Absolute value \\
\hline Mean age of the sampled patients (years) & 67.9 \\
No. of male patients & 38 \\
No. of female patients & 19 \\
No. patients with presence of delirium & 20 \\
No. of patients with absence of delirium & 37 \\
\hline
\end{tabular}

With the purpose of simultaneously identifying the main risk factors for the development of delirium in patients hospitalized in the IDCU- HGO and the ones that can be modified by nurses, 16 variables previously found in the literature review were assessed in each observation performed. The results are shown in Tables 2 and 3.

\section{Table 2}

Risk factors for the development of delirium

\begin{tabular}{|c|c|c|}
\hline & $\begin{array}{l}\text { No. of. observations with } \\
\text { presence of delirium }\end{array}$ & $\begin{array}{l}\text { Partial \% of observations with } \\
\text { presence of delirium per } \\
\text { analyzed variable }\end{array}$ \\
\hline Patients with oral feeding & 18 & $28.57 \%$ \\
\hline Patients fasting & 7 & $43.75 \%$ \\
\hline Patients fed by nasogastric tube & 12 & $75 \%$ \\
\hline Increased urinary output & 2 & $25 \%$ \\
\hline Normal Urinary output & 23 & $33.82 \%$ \\
\hline Decreased urine output & 12 & $60 \%$ \\
\hline Normal renal function & 18 & $32.14 \%$ \\
\hline Altered renal function & 19 & $47.5 \%$ \\
\hline Patients without central venous catheter & 19 & $38 \%$ \\
\hline Patients with central venous catheter & 18 & $39.13 \%$ \\
\hline Patients without arterial line & 14 & $29.79 \%$ \\
\hline Patients with arterial line & 23 & $46.94 \%$ \\
\hline Patients without other biodevices & 3 & $21.43 \%$ \\
\hline Patients with other biodevices & 34 & $41.46 \%$ \\
\hline Patients who received visits & 26 & $36.62 \%$ \\
\hline Patients who did not receive visits & 11 & $44 \%$ \\
\hline Patients without sensory changes & 20 & $36.36 \%$ \\
\hline Patients with visual and/or hearing impairment & 17 & $41.46 \%$ \\
\hline Patients not medicated with benzodiazepines & 26 & $34.21 \%$ \\
\hline Patients medicated with benzodiazepines & 11 & $55 \%$ \\
\hline Patients not medicated with propofol & 32 & $35.56 \%$ \\
\hline Patients medicated with propofol & 5 & $83.33 \%$ \\
\hline Patients with no need for invasive mechanical ventilation & 29 & $34.94 \%$ \\
\hline Patients on invasive mechanical ventilation & 8 & $61.54 \%$ \\
\hline Patients with no need for non-invasive mechanical ventilation & 25 & $33.78 \%$ \\
\hline Patients on non-invasive mechanical ventilation & 12 & $54.55 \%$ \\
\hline
\end{tabular}


Table 3

Analytical values related to the development of delirium

\begin{tabular}{|c|c|c|}
\hline & Observations with absence of delirium & Observations with presence of delirium \\
\hline Mean leucocytes & $11.29\left(10^{\wedge} 9 / \mathrm{L}\right)$ & $13.76\left(10^{\wedge} 9 / \mathrm{L}\right)$ \\
\hline Mean $\mathrm{PaO}_{2}$ & $99.19(\mathrm{mmHg})$ & $80.79(\mathrm{mmHg})$ \\
\hline Mean $\mathrm{PaCO}_{2}$ & $40.15(\mathrm{mmHg})$ & $48.79(\mathrm{mmHg})$ \\
\hline Mean $\mathrm{HCO}_{3}^{-}$ & $24.73(\mathrm{mmol} / \mathrm{L})$ & $27.49(\mathrm{mmol} / \mathrm{L})$ \\
\hline
\end{tabular}

\section{Discussion}

The results of this study point to the existence of several risk factors leading to the development of delirium. Among the different factors, we will focus our discussion only on the factors that can be modifiable by nurses.

As regards the variable related to nutrition and hydration, we found that delirium was present at the moment of assessment in 37 observations. It should be noted that in seven observations the patients were fasting (43.75\%) and in 12 observations they were receiving enteral feeding (75\%). The studies developed by Torres, Sánchez, and Zarco (2012), Ocádiz-Carrasco, Gutiérrez-Padilha, Páramo-Rivas, Serrano, and Hernández-Ortega (2013) and Raats, Eijsden, Crolla, Steyerberg, and van der Laan (2015) indicate that poor nutrition and dehydration are modifiable risk factors for the development of delirium.

In the study developed by Ocádiz-Carrasco et al. (2013), the authors emphasize the importance of adopting interventions that encourage water intake, and promote nutrition and the maintenance of a clean, cool and hydrated mouth, to allow reducing the incidence of delirium. Thus, nurses should encourage oral feeding whenever possible, either by adapting the type of diet to the patients' condition and preferences or by maintaining a good hygiene and hydration of the oral mucosa, avoiding the use of nasogastric feeding. Castro et al. (2014) confirmed the increased risk of delirium in patients being fed through a nasogastric tube.

In addition to the measures suggested, nurses should also allow and encourage patients to use dental prostheses during hospitalization, so as to facilitate oral feeding. Based on these findings, it should be noted that the nurses' responsibility for this variable is evident. However, the data obtained do not allow us to establish a direct cause-effect relationship, because many other factors related to the patient's condition may also have an impact on this variable.

With regard to the management of invasive devices, and in line with the results found in this study, several authors conclude on the existence of a relationship between the use of invasive devices and the development of delirium in inpatients. Among the observations performed, we found that patients with delirium had a central venous catheter (39.13\%), arterial line (46.94\%) and other biodevices (41.46\%). Regarding the use of other invasive devices, catheterization is underlined by Ocádiz-Carrasco et al. (2013) and De Castro et al. (2014) as a risk factor for the development of delirium. These authors also emphasized that the use of postoperative drains had a similar relationship with delirium. Raats et al. (2015) also indicated that as the procedures become more invasive, the risk of delirium increases.

Health professionals should minimize, whenever possible, the use of invasive devices in the patient treatment, and nurses in particular should raise the awareness of the other professionals to the patients' actual needs, reflecting on potential gains and risks as a team. Risk management is an emerging topic in this type of units and the nurse is one of the main actors in this process. In addition, according to Henao-Castaño and Amaya-Rey (2014), teams should develop evidence-based protocols that sustain their decision-making regarding the dwell time of the different devices, particularly when their use is no longer essential, or when their functionality is compromised.

Along the use of biodevices, infections can also be understood as modifiable risk factors for the development of delirium (Ocádiz-Carrasco et al., 2013). With regard to the total leukocyte count, Ansaloni et al. (2010), De Castro et al. (2014) and Kennedy et al. (2014) concluded that the number 
of white cells is higher in patients with delirium (9.6 \pm 4.3 vs. $8.3 \pm 3.4$ ), which corroborates the results obtained in this study.

The provision of nursing care should comply with the general principles of infection prevention and management, namely hand hygiene, strictly complying with all the existing standards and protocols. From a legal point of view, it should also be emphasized that one of the specific skills of the nurse specialist in the provision of care to critically ill patients aims to maximize "the intervention in the prevention and management of infection of the person in critical condition and/or organ failure ..." (Regulamento $n^{0} 124 / 2011$, p. 8656). The analysis of these variables has several limitations since the condition of critically ill patients is highly complex and it becomes very difficult to isolate variables that interact with each other.

The family visits is also a risk factor modifiable by nurses. In this study, a significant percentage of in the observed patients who did not receive visits showed the presence of delirium (44\%). Ocádiz-Carrasco et al. (2013) highlighted that family support is also an independent risk factor for the development of delirium, so patients are more vulnerable when they have a poor family support. Rosenbloom-Brunton, Henneman, and Inouye (2010) argue that it is essential to engage the family in the prevention and treatment of delirium and that this strategy has allowed reducing its incidence. Since nurses are the health professionals who spend more time with the patients and are in the best position to establish a connection with the family, Henao-Castaño and Amaya-Rey (2014) argue that nurses should not only facilitate, but also promote family visits. Furthermore, the interaction between nurses and patients should also be stimulated, particularly through orientation interventions, such as talking about current issues, maximizing the memory and recalling the past, viewing photos or even allowing patients to listen to their songs of choice (Rosenbloom-Brunton et al., 2010; Ocádiz-Carrasco Et al., 2013).

Uncompensated sensory deficits (visual and/ or hearing impairment) were also identified as modifiable risk factors, as described by Torres et al. (2012), Dasgupta and Brymer (2014), De Castro et al. (2014) and Raats et al. (2015). In De Castro et al. (2014) and Raats et al. (2015), reduced visual acuity was present in most patients with delirium. Reduced hearing acuity was found in a large percentage of patients with delirium (Dasgupta \& Brymer, 2014; De Castro et al., 2014). For this reason, Henao-Castaño and Amaya-Rey (2014) argue that nurses should encourage the use of visual and hearing prostheses in patients previously dependent on these devices, thus improving their ability to perceive and interact with the environment and, consequently, preventing the development of delirium. Therefore, the limitations concerning the use of personal objects by the patients hospitalized in ICUs should be addressed.

Another risk factor identified through the observations was the management and monitoring of the administration of medication for the central nervous system. In this study, $55 \%$ and $83.33 \%$ of the patients medicated with benzodiazepines and propofol, respectively, developed delirium. The scientific evidence found by Torres et al. (2012) confirms that the use of benzodiazepines increases the risk of delirium. Svenningsen et al. (2013) mentioned that the risk increases with the bolus administration of these drugs, when compared with their administration through continuous infusion. Ocádiz-Carrasco et al. (2013) and Svenningsen et al. (2013) refer that the use of propofol is associated with the risk of delirium, which is higher with this medication than with benzodiazepines.

This variable does not depend on the autonomous action of nurses. However, nurses can manage the administration of medication when prescribed in SOS, taking into account the greater or lesser risk for development of delirium. Nurses should, whenever possible, combine these measures with non-pharmacological interventions, such as reducing light and noise during the night, promoting the correct alternation between cycles of sleep and wakefulness, and using a calm and serene tone of voice (Henao-Castaño \& Amaya-Rey, 2014).

In addition to the potential consequences mentioned above, sedation can influence the occurrence of hypoventilation, which, in turn, leads to $\mathrm{CO}_{2}$ retention. According to Ocádiz-Carrasco et al. (2013), hypercapnia is another risk factor for the development of delirium. In this study, patients with delirium had mild hypercapnia ( $48.79 \mathrm{mmHg}$ ). In addition, hypercapnia may contribute to the need for mechanical ventilation, which, based on the results of this study, is also a risk factor for the development of delirium. 
In line with these findings, Svenningsen et al. (2013) showed that $93.5 \%$ of patients on invasive mechanical ventilation had developed delirium. Although these results do not depend on the nurses' autonomous action, nurses can develop interventions aimed to reduce the development of delirium. They may position the patients properly, according to their condition and needs, with a view to promoting comfort and an effective breathing, as well as maintaining an adequate peripheral oxygen saturation.

\section{Conclusion}

The evidence indicates that delirium influences the mortality and morbidity rates of inpatients and that modifiable risk factors for its development have already been identified. Nurses, in particular specialist nurses, have an increased responsibility to develop and maintain a safe therapeutic environment which contributes to decrease the occurrence of delirium. Taking into account the results of this study and the evidence of the reviewed studies, we suggest that nurses could contribute to reducing the incidence of delirium through the promotion of adequate oral feeding and hydration, adjusting the diet to the patients' preferences, encouraging the use of dental prostheses, maintaining a good hygiene and hydration of oral mucosa, and avoiding, when possible, nasogastric feeding; the prevention and management of healthcare-associated infections, adequately managing invasive devices; the promotion of family visits, stimulating their interaction with the patients through conversations that allow them to stay oriented, both in terms of time and space; the promotion of the use of existing visual and hearing prostheses, improving the patients' ability to perceive and interact with their surroundings; the adequate management of SOS medications, using non-pharmacological techniques more frequently to reassure patients; the promotion a proper patient's positioning and oxygen therapy, combined with a timely aspiration of secretions, in order to delay as much as possible the need for mechanical ventilation. We believe that this study was important to reflect on the need for a systematized assessment of the presence (or absence) of delirium in patients hospitalized in the IDCU so that prevention or treatment measures can be adopted. However, we are aware that the time period allocated for the development of this study has limited the data collection process and the subsequent analysis of the association between variables. For this reason, these results cannot be generalized and can only be applied to our sample.

\section{References}

American Association of Critical-Care Nurses (AACCN). (2011). Practice Alert: Delirium assessment and management. Consultado em: 2015, Novembro 12. Retrieved from: http:// www.aacn.org/WD/practice/docs/practicealerts/deliriumpractice-alert-2011.pdf

American Psychiatric Association. (2014). Diagnostic and statistical manual of mental disorders ( $5^{\text {th }} \mathrm{ed}$.). Washington, WA: Author.

Ansaloni, L., Catena, F., Chattat, R., Fortuna, D., Franceschi, C., Mascitti, P., \& Melotti, R. M. (2010). Risk factors and incidence of postoperative delirium in elderly patients after elective and emergency surgery. The British Journal of Surgery, 97(2), 273-280. doi: 10.1002/bjs.6843

Barr, J., Fraser, G., Puntillo, K., Ely, E., Gélinas, C., Dasta, J., . . . Jaeschke, R. (2013). Clinical practice guidelines for the management of pain, agitation, and delirium in adult patients in the intensive care unit. Critical Care Medicine, 41(1), 263306. doi: 10.1097/CCM.0b013e3182783b72

Dasgupta, M., \& Brymer, C. (2014). Prognosis of delirium in hospitalized elderly: Worse than we thought. International Journal of Geriatric Psychiatry, 29(5), 497-505. doi: 10.1002/ gps. 4032

De Castro, S. M., Ünlü, C.., Tuynman, J. B., Honig, A., van Wagensveld, B. A., Steller, E. P., \& Vrouenraets, B. C. (2014). Incidence and risk factors of delirium in the elderly general surgical patient. American Journal of Surgery, 208(1), 26-32. doi: 10.1016/j.amjsurg.2013.12.029

Faria, R. B., \& Moreno, R. P. (2013). Delirium na unidade de cuidados intensivos: Uma realidade subdiagnosticada. Revista Brasileira de Terapia Intensiva, 25(2), 137-147. doi: 10.5935/0103-507X.20130025

Henao-Castaño, Á. M., \& Amaya-Rey, M. P. (2014). Nursing and patients with delirium: A literature review. Investigación E Educación en Enfermería, 32(1), 148-156. doi: 10.1590/ S0120-53072014000100017

Kennedy, M., Enander, R. A., Tadiri, S. P., Wolfe, R. E., Shapiro, N. I., \& Marcantonio, E. R. (2014). Delirium risk prediction, healthcare use and mortality of elderly adults in the emergency department. Journal of the American Geriatrics Society, 62(3), 462-469. doi: 10.1111/jgs.12692

National Institute for Health and Care Excellence. (2014). Delirium in adults: Quality standard. Retrieved from http://www.nice.org.uk/guidance/qs63/resources/deliriumin-adults-2098785962437 
Neves, H., Silva, A., \& Marques, P. (2011). Tradução e adaptação cultural da escala de confusão de NEECHAM. Revista de Enfermagem Referência, 3(3), 105-112. doi: 10.12707/ RII1052

Ocádiz-Carrasco, J., Gutiérrez-Padilla, R. A., Páramo-Rivas, F., Serrano, A. T., \& Hernández-Ortega, J. L. (2013). Preventive program for postoperative delirium in the elderly. Cirugía y Cirujanos, 81(3), 181-186.

Organização Mundial de Saúde. (2011). Estrutura conceptual da classificação internacional sobre segurança do doente: Relatório técnico final (Direcção-geral da Saúde, Trad.). Lisboa, Portugal: Direcção-Geral da Saúde. (Obra originalmente publicada em 2009).

Regulamento $\mathrm{n}^{\mathrm{0}}$ 124/2011 de 18 de fevereiro. Diário da república $n^{0}$ 35/2011 - $2^{a}$ Série. Ordem dos Enfermeiros. Lisboa, Portugal.

Regulamento no 361/2015 de 26 de junho. Diário da República $n^{o}$ 123/2015 - $2^{a}$ Série. Ordem dos Enfermeiros. Lisboa, Portugal.Raats, J. W., van Eijsden, W. A., Crolla, R. H., Steyerberg, E. W., \& van der Laan, L. (2015). Risk factors and outcomes for postoperative delirium after major surgery in elderly patients. PloS One,10(8), e0136071. doi: 10.1371/ journal.pone.0136071

Rosenbloom-Brunton, D., Henneman, E., \& Inouye, S. (2010). Feasibility of family participation in a delirium prevention program for hospitalized older adults. Journal of Gerontological Nursing,36(9), 22-33. doi: 10.3928/0098913420100330-02

Svenningsen, H., Egerod, I., Videbech, P., Christensen, D., Frydenberg, M., \& Tønnesen, E. K. (2013). Fluctuations in sedation levels may contribute to delirium in ICU patients. Acta Anaesthesiologica Scandinavica, 57(3), 288-293. doi: 10.1111/aas. 12048

Torres, D., de Sánchez, C. R., \& Zarco, l. A. (2012). Identificación de los factores de riesgo encontrados en pacientes mayores de sesenta años que desarrollaron delírium durante su hospitalización en el Hospital Universitario de San Ignacio, en Bogotá, Colombia. (Spanish). Universitas Médica, 53(4), 365-374.

Vanderbilt University Medical Center. (2011). Top 10 Retrieved from http://www.icudelirium.org/docs/Top_10_Tips_for_ Teaching_Delirium_Monitoring.pdf 